\title{
A Cornerstone Design Module in First Year ENGINEERING
}

\author{
Peter M. Ostafichuk, David Sommer, and Carol P. Jaeger \\ University of British Columbia \\ ostafichuk@mech.ubc.ca
}

\begin{abstract}
This paper describes a new five-week cornerstone design module at the conclusion of first year engineering at the University of British Columbia (UBC). The objective of this cornerstone module is to bring together the multiple course themes-developed over the preceding six modules and 18 academic weeks-into a single, integrative and culminating experience. The module builds on the previous course topics, and specifically emphasizes design, stakeholder consultation, prototyping, sustainability, and communication in a unified project experience. Through a mix of analytical and physical prototyping, teams design a pilot rainwater harvester system for small, remote communities. Teams specify the system components in their design, and submit those through an online form. All systems are then simulated off-line in a detailed MATLAB model that tracks weather, physical performance, cost, maintenance, health and safety risks, and more. The culminating event for the module is a formal oral presentation followed by a timelapse video of the simulations of the different teams' rainwater harvester system designs.

The outcomes to the module have been very positive. The module has successfully run for three years with over 400 teams. Feedback through surveys shows students find the cornerstone project meaningful and helpful in developing their ability to use simulation and numerical modelling in design. Students have also rated the module highly in terms of the relevance to their degree, and the importance of the learning outcomes to engineers. Primary challenges noted to date include inequities in student workload within a team, due to shifting priorities as final exams approach, and ability to update the project each year to maintain a new challenge for each cohort.
\end{abstract}

Keywords: first year engineering, cornerstone project, design project, simulation, prototyping

\section{INTRODUCTION}

This paper explores the development of a culminating design experience in a new first year introduction to engineering course at the University of British Columbia (UBC). The use of a "design spine" to link the years of an engineering program is becoming common [7],[8]. In particular, first year curricula are more frequently including design experiences [6]. This is driven, in large part, by pedagogical benefits; however, accreditation requirements - specifically the need to show that depth, complexity, coverage, expectations, and use of material changes over the years of the degree [2] —also play a role.

As part of a curriculum redesign process at UBC, two new introduction to engineering courses were unveiled in 2015-16, and they feature a concluding project that integrates the various topics and experiences of the two courses together (i.e. a cornerstone project). An extensive, year-long consultation process was undertaken in the development of the new courses. Several key goals for the courses emerged through this process:

- showcase engineering and what engineers do,

- highlight how engineers balance trade-offs and design solutions to open-ended problems,

- emphasize the role sustainability plays in decisionmaking by engineers, and,

- impress upon students the role professionalism and ethics play in the life of an engineer.

In addition, we recognized it was important to

- increase students' sense of belonging to the engineering profession and community,

- increase excitement about engineering, and,

- help students understand what makes each engineering discipline unique, in order to help them select their programs for second year.

To the last point, we endeavoured to showcase as many of the engineering disciplines as possible in each project or case study used in the new curriculum. We also strived to devise projects and cases with a clear societal or personal connection, shown to appeal more to female students [9], (i.e. avoid combative projects, such as "battling robots").

As will be demonstrated, we believe we have managed to create a rich, engaging, and meaningful project that addresses many of the broad course- and curriculum-level goals, while also satisfying numerous constraints. Section 2 of this paper outlines the specific course context of the highlighted cornerstone module; Section 3 details of the module design and implementation; Section 4 presents results from several years of course operation and student surveys; and Section 5 includes a discussion of the successes, challenges, and accreditation implications. 


\section{COURSE CONTEXT}

Starting in the 2015-16 academic year, two new introduction to engineering courses, APSC 100 and APSC 101 , were offered at UBC [12]. The APSC 100 course is taken by all first year engineering students at UBC (approximately 900), while the APSC 101 course is taken primarily by direct entry (i.e. non-transfer) students (approximately 800). The APSC 100 course runs in the fall term and consists of four modules: introduction to design and prototyping; introduction to stakeholders and decisionmaking; CAD and rapid prototyping; and professionalism and ethics. The APSC 101 course runs in the spring term with APSC 100 as a prerequisite. There are three modules in APSC 101: engineering tools (including physical prototyping, risk management, and drawings); sustainability; and a cornerstone project. In addition, teamwork, communication, professional feedback, and the role of engineering in society are all key themes that are emphasized in all modules. Module 7, the cornerstone project, is the focus of this paper. The intent of the project is to integrate all key topics from APSC 100 and 101 into a single, culminating 5-week experience.

The APSC 100 and 101 courses are taught in a blended learning format, with extensive use of online video and exercises to develop initial competency with material. The courses draw extensively from the Team-Based Learning approach [13], and feature a repeating weekly cycle of online material, opening large class with team quiz, studio (i.e. lab/tutorial), and concluding large class. Students in the courses are assigned to teams by the course instructors. There are approximately 135 teams in the APSC 101 course with a nominal size of 5 or 6 members, but there are a few teams of 4 and a few teams of 7 based on timetabling constraints. The same teams persist for the entire course, and they are intentionally different from the teams in APSC 100 in order to avoid pre-established sub-groups [11]. APSC 101 teams are formed by trying to distribute students by APSC 100 grade as heterogeneously as possible [1], and all efforts are made to ensure female students are not left alone on a team [5]. Further details in terms of course context were reported by the course instructors in 2016 [12]. The actual design and implementation of the cornerstone module is outlined in the following section.

\section{CORNERSTONE MODULE DESIGN}

Below, the course-level goals and constraints are introduced, followed by the project (the design of a rainwater harvester), and then the module timeline and key topics. This section concludes with details of the system specifications the students design to, and the final simulation tool that models the operation of each team's rainwater harvester system over five years of operation.

\subsection{Goals and Constraints}

The overall goal of the cornerstone design module is to provide an integrative culminating engineering experience for the APSC 100 and 101 courses. The intent has been to draw together as many different major course concepts as possible, while giving teams a final opportunity in first year to employ the design process and manage a project. The key elements that are emphasized in the module include

- the design process,

- stakeholder engagement,

- physical and analytical prototyping,

- sustainability (specifically systems thinking, lifecycle thinking, and resiliency), and

- communication.

It was recognized early in the module creation that a design-build project, with the production of a physical artifact as a deliverable, might be challenging for students. This came from a common experience in other courses that the physical realization of a design often required substantially longer than students had expected, and the quality of the final design product under such circumstances was compromised. Recognizing that this module occurred at the end of first year-as students' attention was turning to final exams - it was decided to restrict the output of the project to a virtual design. This was done to reduce workload, reduce stress, and reduce the chance of an unsatisfying or discouraging project outcome as the lasting course memory. Physical prototyping was incorporated in the module through carefully planned benchtop experiments, thereby demonstrating the use focused, pilot-scale prototyping in engineering work.

In referring to the broad first year curriculum development goals, additional qualities for the cornerstone project were identified. Namely, the project should

- be meaningful, and engage students in addressing an important societal problem,

- have realistic stakeholders, and highlight connections of engineering with society,

- have technical depth and allow the use of real engineering tools and techniques,

- include realistic communications deliverables and provide opportunities to enhance communication and feedback skills, and,

- be inspiring and fun, and provide a positive conclusion to first year.

As an additional consideration, through consultation with the engineering programs served by the common first year, several programs indicated that much of the numerical work their students undertake is done using spreadsheets (specifically, Excel). As there are no formal courses which teach Excel to engineering students at UBC, the opportunity to use Excel as the prototyping tool to execute this cornerstone project was identified. 


\subsection{Rainwater Harvester (RWH) Project}

The project involves the design of a rainwater harvester system (RWH). The problem is introduced in the preceding course module, which focuses on sustainability and water scarcity. The context is the design of a decentralized water treatment system for small and remote communities. The project need is presented by highlighting the large number of drinking water advisories in Canada, particularly in remote Indigenous communities.

The stakeholders for the project are fictitious, but are based on a real community facing challenges with accessing sufficient clean water. RES'EAU WaterNET (http://www.reseauwaternet.ca/), has been working with Van Anda, a small, remote settlement contextually similar to the one imagined in the project. Van Anda is an unincorporated community located on Texada Island in the Strait of Georgia. A curriculum developer assisting with the module travelled to Van Anda with an engineer from RES'EAU. The curriculum developer met with Van Anda residents responsible for ensuring a clean water supply for the community. In addition to researching and documenting the problem context, the curriculum developer conducted and recorded video interviews with Van Anda community members and the RES'EAU engineer. The edited video interviews are used in the course as a surrogate for direct contact by teams with stakeholders, and the goals and challenges of the people in Van Anda are taken to be representative of those for the fictitious stakeholders in the module.

A fictitious pilot site consisting of a two-occupant house situated on given topography is provided, along with several years of historic rainfall data for select weather stations in the surrounding region. The overall system architecture is shown schematically in Fig. 1.

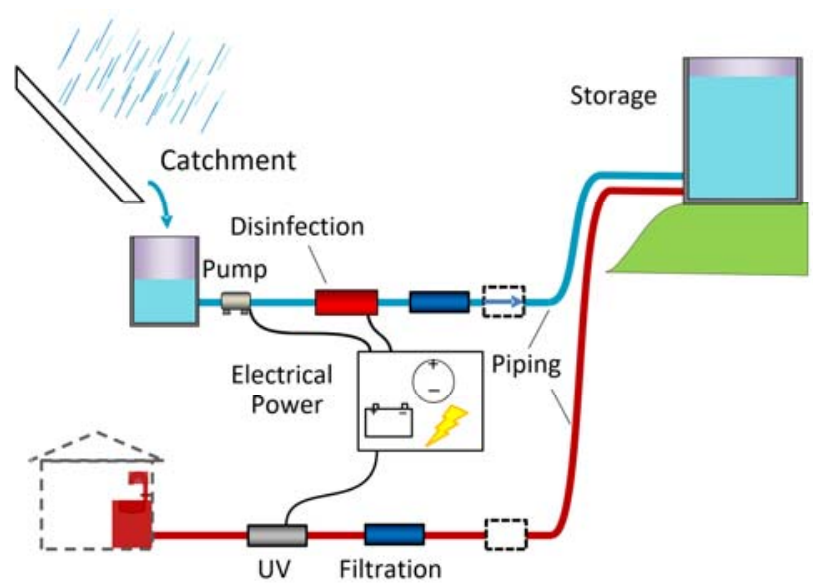

Fig. 1: RWH system schematic

The system consists of a rainwater collection (i.e. catchment) area and tank, a pump and chemical disinfection system (chlorine or ozone), an electrical power system, filters, specified check valves and other fittings, an elevated storage tank, a UV disinfection system, and the two-person dwelling. Teams are provided a catalog of components to select from. For example, they can select between three different pump models, all with different pressure-flow curves, initial costs, and maintenance intervals. The complete set of parameters and considerations teams design to is given in Section 3.4.

\subsection{Project Timeline and Topics}

The module fits in the last five weeks (Weeks 9 to 13) of the APSC 101 course in the final term of first year, although some activities take place at the end of the preceding module (Week 8 of the course). A detailed list of activities and topics is provided, by week, in Table 1 .

Table 1: Module Schedule

\begin{tabular}{|c|c|c|c|c|}
\hline Week & Project phase & Online topics & Class topics & Studio topics \\
\hline 8 & Introduction & - Stakeholder interviews & - Water consumption estimates & (Module 6 activities) \\
\hline 9 & Specification & $\begin{array}{l}\text { - Stakeholder satisfaction } \\
\text { - Introduction to spreadsheets } \\
\text { - Spreadsheets as modeling } \\
\text { tools }\end{array}$ & $\begin{array}{l}\text { - Setting specifications } \\
\text { - Prototypes in Module } 7 \\
\text { - Intro to water purification }\end{array}$ & 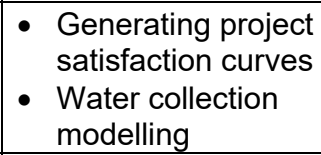 \\
\hline 10 & Modeling & $\begin{array}{l}\text { - Modelling a RWH system } \\
\text { - Basic fluid mechanics }\end{array}$ & $\begin{array}{l}\text { - Using conditional statements } \\
\text { in Excel } \\
\text { - RWH power system modelling }\end{array}$ & $\begin{array}{l}\text { - Develop RWH } \\
\text { system model }\end{array}$ \\
\hline 11 & Analysis & $\begin{array}{l}\text { - RWH fluid mechanics } \\
\text { - Pressure and flow } \\
\text { - Fitting curves to data }\end{array}$ & $\begin{array}{l}\text { - } \begin{array}{l}\text { Pressure and flow } \\
\text { relationships } \\
\text { - Lab data analysis for use in } \\
\text { project }\end{array} \\
\end{array}$ & $\begin{array}{l}\text { - Physical labs on } \\
\text { pressure and flow }\end{array}$ \\
\hline 12 & Implementation & $\begin{array}{l}\text { - RWH implementation } \\
\text { - Diversity and bias* }\end{array}$ & - Implicit bias* & $\begin{array}{l}\begin{array}{l}\text { RWH system } \\
\text { integration }\end{array} \\
\end{array}$ \\
\hline 13 & Recommendation & $\begin{array}{l}\text { - Teams and team } \\
\text { development }\end{array}$ & $\begin{array}{l}\text { - Team functioning } \\
\text { - Course review* }\end{array}$ & $\begin{array}{l}\text { - } \begin{array}{l}\text { Project } \\
\text { presentations and } \\
\text { simulations }\end{array} \\
\end{array}$ \\
\hline
\end{tabular}

CEEA18; Paper 154

University of British Columbia; June 3-6, $2018 \quad-3$ of $8-$ 
In Week 8, in online activities, students watch a series of interviews with Van Anda residents and then complete an online questionnaire about what needs they feel were most important for the community. The project is formally introduced in the second half of the last class of Week 8, and students begin an activity on estimating water consumption needs for residents of the pilot site (based on the Van Anda interview video). The video and class activity responses are processed by the instructional team and used to generate key stakeholder attributes for the Week 9 studio. In that studio, students translate the key stakeholder attributes into requirements (and set the requirement threshold levels), as well as into evaluation criteria, and here they determine the relationship between the attribute level and the stakeholder satisfaction (i.e. curve shape and key values). The studio responses are entered in an online form, and the instructional team again processes these results to establish a common set of requirements and evaluation criteria for all teams in the course for the project. In other words, each team plays the roles of both engineers and stakeholders in the specification process; due to the crowd-sourcing aspect, the final specifications each team designs to are dictated by people from outside the team, mimicking the input of external stakeholders.

Through Weeks 10, 11, and 12, students are given increasingly complex information on the RWH system physics and components. They are introduced to basic concepts of fluid mechanics, as well as the use of spreadsheets as a numerical modelling and simulation tool. Included is guidance on integrating physical and analytical prototypes together to build a complex simulation.

The items noted with "**" in the table are related to team function - they are not central to the project, but they are important in the overall course. These topics were deliberately placed at the end of the course to facilitate reflection and discussion on team experiences through the term. Furthermore, these topics were placed at the end of the module such that all theory and technical content required to complete the project was available to students with two full weeks to go. Students were able to complete the detailed work on their projects in parallel with these class topics.

The final project deliverables, including a presentation and simulation, occurred in the final studio, in Week 13 of the course. More complete details are provided in the following section.

\subsection{RWH System Specification and Simulation}

There are two primary deliverables for the RWH project: a set of design specifications used to simulate system performance, and an oral presentation justifying design decisions. The design specifications include up to 24 component choices and parameter values in order to define a complete RWH system (see below). In the final studio of the module, all teams deliver an oral presentation outlining their design and recommendations, and then a video showing a time-lapse simulation of all system designs is presented.

Designs are scored based on overall stakeholder satisfaction using the crowd-sourced specifications created in Week 9. Using the 2017-18 academic year as reference, the key performance attributes used to score the student designs are

- average daily volume of treated water the system can deliver,

- peak on-demand water flow rate supplied,

- relative cost to the status quo (i.e. shipping water in bulk from the mainland),

- health and environmental risk exposure (e.g. due to shipping and handling chlorine and/or diesel),

- greenhouse gas emissions (relative to status quo),

- number of maintenance events per year, and

- number of days of reliable operation per year.

The overall project score is based on a linear weighted sum of the stakeholder satisfaction scores from the above attributes. Each attribute has an associated requirement (with the threshold value also crowd-sourced by the student teams) that had to be met for the design to be considered acceptable. In addition, there are requirements on water disinfection levels and system components to be used. In operation, if there is a problem with the system (e.g. the storage tank runs dry or the batteries become fully discharged such that the UV disinfection system cannot run), the team is charged the cost to ship bulk water in for that day, and stakeholder satisfaction with reliability is diminished.

In their submission, teams declare a daily water supply volume they claim their system can supply. In addition, there are over 20 different parameter choices and values they must specify in their system:

- the catchment system, including catchment type, catchment area, and catchment tank volume,

- the pumping system, based on pressure-flowrate curves for several candidate pumps,

- the treatment system, including filter sizes and locations, and the type of chemical treatment (chlorine or ozone) used in addition to UV treatment,

- the storage system, including the volume, location on the property, and supporting base height for the storage tank, and

- the power system, based on either a photovoltaic system (including quantity and model of solar panel) or a diesel generator, as well as the number of batteries.

The system specifications are submitted by teams using an online form. Raw data is extracted from the form in bulk as a .csv file and then processed through a MATLAB simulation to generate a performance time history over five 
years of operation. The simulation includes detailed models of the RWH physics and components, and weather data different from the sample data provided to teams. For the studio, after teams have delivered their presentations outlining their design process and recommendations, the simulated performance of all teams in that studio is video projected with a time compression of 1-minute per year. During these five minutes, teams see fluctuating weather data, and a display of key system parameters for each team, including cumulative cost, water tank level, system status, number of maintenance events and days without water, and so on. An example screenshot of the simulation display, with three teams viewable, is shown in Fig. 2.
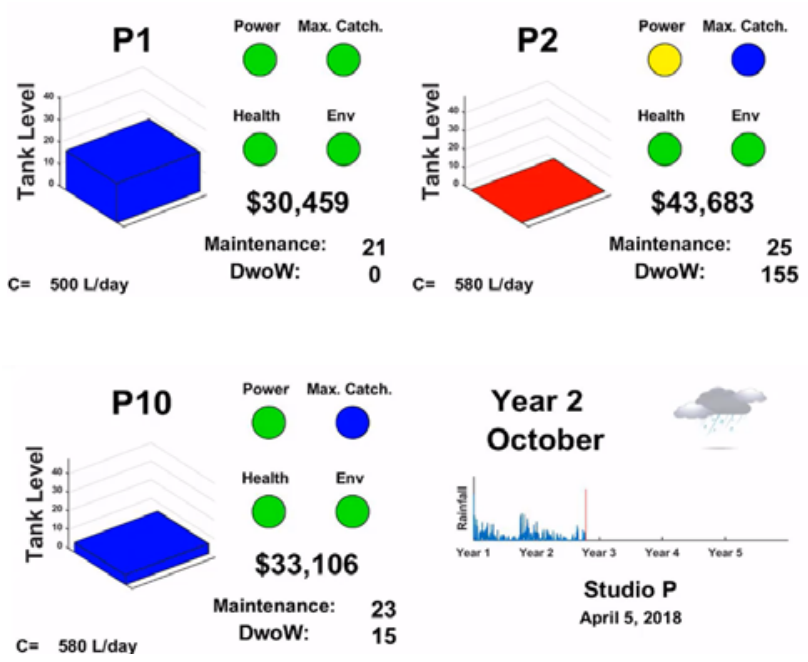

Fig. 2: Sample screenshot from studio simulation display

In the presentations, assessments are conducted by instructors as well as the student peers in the room. This use of peer evaluation is well-supported in the literature [3],[4],[14], and it builds on work that occurs earlier in the courses on training students how to give fair, honest, and effective feedback [10].

\section{RESULTS}

General observations about the cornerstone module are provided below, followed by student survey results for the module and for the course, and finally some observations regarding student workload and team function.

\subsection{General Comments and Observations}

We have been extremely pleased with the cornerstone design module. We believe it has successfully addressed many of the broad curriculum-level goals listed in Section 1 , as well as the module-level goals from Section 3.1. Anecdotally, the increase in comfort we see with students using virtual prototypes (i.e. simulations) to make design decisions, and the engagement and interest during the final studio simulations, have been particularly encouraging.

Other areas of success include the ability of our team to manage the data flow in the student designs and simulations. Teams submit their design specifications by noon the day before their studio, and we are able to run simulations, and generate and compile final simulation videos in a matter of hours. In three years, with almost 50 studio sessions, we have $100 \%$ success in being able to present the final simulation videos on time. We attribute this success to extensive use of online submission forms with validation and error-checking and automated processing routines, but also to having dedicated and welltrained people to run and compile the simulation results.

In terms of team performance, we typically see roughly $80 \%$ of teams creating solutions that meet all specification requirements. The average score (i.e. weighted stakeholder satisfaction metric) for the simulated RWH systems is approximately $70 \%$, based on the crowd-sourced specification data. Grading of the designs has been very straightforward; we take the raw satisfaction score and add $10 \%$ if requirements are all met, and deduct $10 \%$ if they are not. This naturally yields respectable project grades with an average of just under $80 \%$ and a standard deviation of roughly $15 \%$ (i.e. under this system, we see an appropriate average with good dispersion).

\subsection{Module 7 Survey}

An optional and anonymous survey is given to students at the end of Module 7 each year. Among other questions, the survey includes nine questions related to the key module goals. These are shown below and are based on a 5-point Likert scale (strongly disagree, mildly disagree, neutral, mildly agree, strongly agree).

- Q1. The module was effective at introducing the use of simulation and numerical modeling in design

- Q2. I feel more confident in my ability to use spreadsheets as a result of the module

- Q3. I feel I will now be able to take on more complex design problems

- Q4. The project was fun and engaging

- Q5. The project was meaningful - it felt like something where an engineer could have a positive impact in the world

- Q6. I was proud of the rainwater harvester system my team developed

- Q7. I was proud of the presentation my team delivered

- Q8. My ability to work as a member of a team has improved as a result of the module

- Q9. My comfort level in making and justifying engineering decisions has improved as a result of this module 
The results from the 2017-18 academic year are given below in Fig. 3. Statistically significant $(p \leq 0.05)$ differences between male and female responses are indicated with a "*" in the horizontal axis.

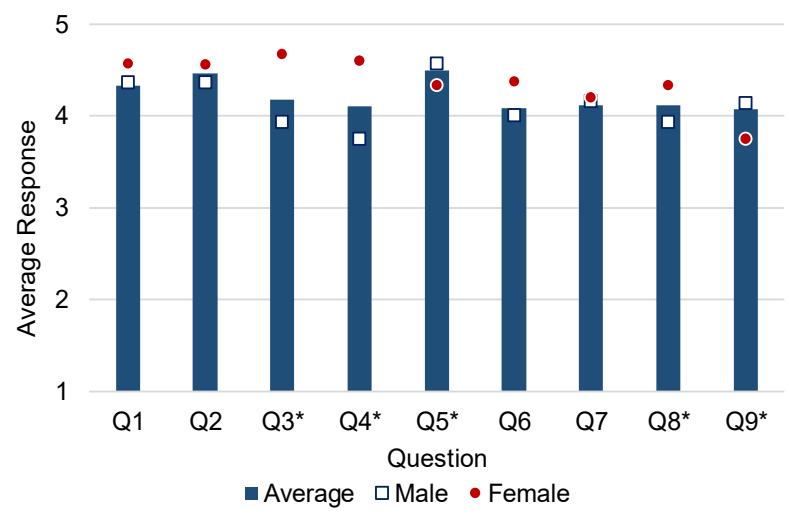

Fig. 3: Module 7 survey data for 2017-18 year. Responses $(n=41)$ are on a 5-point Likert scale, with $1=$ strongly disagree to $5=$ strongly agree.

Although the sample size at the time of this paper is small (this is $5 \%$ of the cohort, but the survey is ongoing), the results are very encouraging. The average rating across all prompts corresponds to at least mild agreement, and in no prompt did fewer than $88 \%$ of respondents agree. Also encouraging was the fact that female respondents generally gave very favourable ratings, which aligns with our intention to create course materials that help to attract and retain female students.

\subsection{Course Exit Survey}

In addition, an optional and anonymous course exit survey for all students in APSC 100 and 101 is delivered after the end of term. In this survey, among other questions, students ranked the seven modules from APSC 100 and 101 on three scales:

- Enjoyment: how much they enjoyed the module topics and project,

- Impact: how the module contributed to their development as a first year engineering student, and,

- Importance: how significant the topics in the module were to engineering.

The same survey has been administered for three academic years (2015-16, 2016-17, and 2017-18), although the "importance" ranking question was added in 2017-18. The relative ranking of modules is shown in Fig. 4, where 7 represents a top ranking (100\% of respondents ranked it as the first) and 1 represents a bottom ranking $(100 \%$ of respondents ranked it last). With seven modules, an average ranking corresponds to a value of 4 . The response rates to the surveys were $134(18 \%), 81(11 \%)$, and $41(5 \%$, but still underway at the time of this paper). As shown, students ranked the capstone module as about average in terms of enjoyment, but highest in terms of the impact on their development and highest in terms of the importance of topics for engineering.

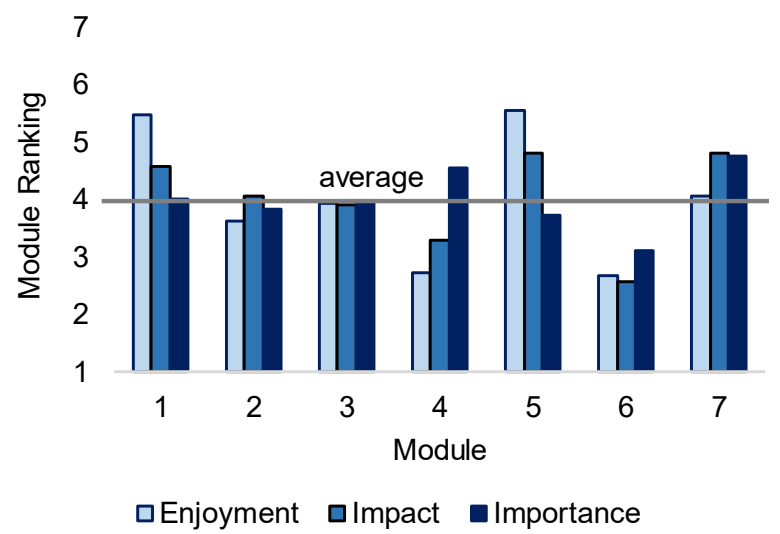

Fig. 4: Student ranking of seven modules from APSC 100 and APSC 101 (the capstone project is Module 7)

It is important not to read too much into Fig. 4, since it only compares the cornerstone module to other experiences in the same courses. Interestingly, Modules 1 and 5 both have design-build elements, and Modules 2, 4, and 6, involve case studies; this clearly suggests that, at least in terms of student enjoyment, having a project with a physical artifact as an output is most appealing.

\subsection{Workload and Team Function Issues}

Lastly, we have become increasingly aware of imbalances in student workload in Module 7, compared to other modules. Some students commented that they were working much harder than their teammates, or that some teammates stopped contributing. As noted previously, we initially anticipated upcoming final exams at the end of term would be a stressor or distraction, and hence we deliberately avoided a design-build project for Module 7. It appears that we are still seeing this effect with some teams, so we asked a question on the 2017-18 Module 7 survey asking students to report the percentage of work they personally took on in the project, as well as the percentage of work each of their teammates took on.

Survey respondents claimed to work, on average, 50\% more than an equitable amount for their team. On a team with $x$ people, each person's contribution should nominally be $100 \% / \mathrm{x}$ of the work. Referring to the bars in Fig. 5, on a 5-person team, survey respondents claimed they actually did $118 \%$ of their share (i.e. $24 \%$ of the total project work, instead of $20 \%$ ). As the team size increased, the average reported contribution by survey respondents increased: for 6 -person teams, respondents said they contributed $144 \%$ of their share ( $24 \%$ of the total instead of $17 \%)$, and for 7 person teams, they claimed $223 \%$ of their share $(32 \%$ instead of 14\%). 


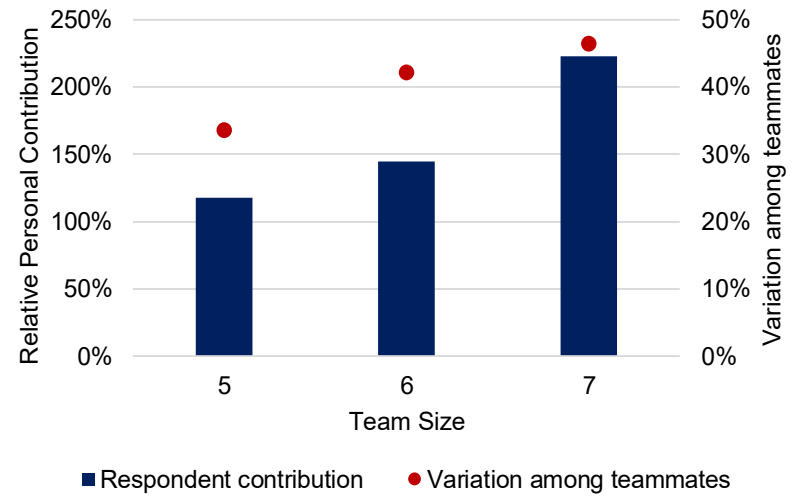

Fig. 5: Reported relative contributions of teammates. Bars indicate the respondents' claimed contribution relative to an equitable contribution, and dots indicate the average deviation in contribution between the remaining teammates (not including the respondent).

We recognize that these results are susceptible to selfattribution bias, and that it is entirely possible, if not likely, that the survey respondents tend to be those who are more engaged in the course and their teams and would be more likely to take on greater contributions. However, in the survey, respondents also reported contributions for each of their teammates, and the average deviation of these numbers (the dots in Fig. 5) also increases with team size. In other words, not only do individuals on larger teams claim they do more than their share of the work, but they also claim there is greater disparity on how the remaining work is divided amongst the rest of the members.

This data is preliminary, but it suggests significant inequities exist (or are at least perceived) in project workload, and care should be taken in setting the scope for a project that occurs at the end of term. It also suggests greater equity is found by avoiding larger teams.

\section{DISCUSSION AND CONCLUSIONS}

In this section, the successes, challenges, and some thoughts on accreditation implications are discussed.

\subsection{Successes}

We believe the cornerstone design module, and in particular the RWH project, have been great successes. The student survey responses suggest the students see value in the module in terms of the importance for engineering and the contribution of the work to their development as engineers. In addition, there is broad student agreement, especially from female students, that the project is achieving our intended goals. We see the RWH as a challenging project, but are encouraged that students complete it successfully. Approximately $99 \%$ of teams submit a functioning design, and $80 \%$ of those submit a design that fully meets all project requirements, even though students never get access to the actual simulator or weather data. Moreover, students express a sense of accomplishment in completing what initially appears to them to be an overwhelming project. Looking at performance on the course final exam, where we ask questions relating to the physics and engineering science underlying the RWH, we see quite strong student performance (approximately a $70 \%$ average, which is typical across all topics in the course).

Other aspects of the RWH project we see as successes include the ability to incorporate real input from (proxy) stakeholders in a course with over 800 students, and the ability to showcase aspects from multiple engineering disciplines (chemical, civil, mechanical, electrical, and computer) in a single, socially meaningful project.

\subsection{Challenges}

The primary challenges we are still working to address include issues relating to unequal student workload, as well as the student desire for a design-build project (rather than a virtual project). In addition, we are planning now for how to train new personnel to manage data collection and simulation for future years, to ensure our smooth an expedient processing of the simulations continues. On a similar note, we are aware that students across years talk to each other, and therefore we update aspects of the project each year so an optimal solution one year might not work the next; this is a challenging and resource-intensive process. Lastly, each project does have a limited shelf-life, and we are cognisant that the RWH project will need to be replaced at some point. A significant effort went into its development, and so we are looking at how to eventually replace the project without having to invest the same amount of resources again.

\subsection{Accreditation Considerations}

To close, we present a few of the considerations regarding outcome assessment for accreditation, as they relate to this module. The module content touches on multiple graduate attributes, including instruction in the hydrostatics and hydrodynamics necessary to understand the RWH system (natural science), as well as information on chemical and physical water treatment, pumping and flow losses, photovoltaics and battery operation (engineering science). Through the project, students learn to use spreadsheets as an analytical prototyping tool, and specifically to simulate performance of a physical system (engineering tools). Commercially available physical data (e.g. pump curves) are provided, but students determine other system parameters (e.g. loss coefficients) through scale-model experiments (investigation). Students need to 
carefully conduct their experiments and properly analyze the resulting data, as these become parts of their system models. Importantly, students weigh environmental, health, economic, risk, life-cycle, and resiliency considerations in sustainability, and base complex decisions on two years of historical weather data to design their system for future conditions. In addition, the module is rich in design, teamwork, and communication. We gather extensive accreditation data through the course, including data on teamwork, communication, and design through rubrics, as well as data on the engineering knowledge base, sustainability, and engineering tools developed through embedded final exam questions.

\section{Acknowledgements}

We wish to thank the University of British Columbia Teaching and Learning Enhancement Fund (TLEF) for funding the work to redevelop our first year engineering curriculum. We also wish to than RES'EAU WaterNET and the people of Van Anda for their willingness and assistance in creating meaningful course resources.

\section{References}

[1] J.L. Brickell, D.B. Potter, M.F. Reynolds, and R.D. Cosgrove, "Assigning Students to Groups for Engineering Design Projects: A Comparison of Five Methods," Journal of Engineering Education, Vol. 83, Issue 3, 259-62, July 1994.

[2] Canadian Engineering Accreditation Board, "Questionnaire for Evaluation of an Engineering Program," Ottawa, $13 \quad$ Nov, 2017. https://engineerscanada.ca/sites/default/files/accreditatio n/EN_2017_Questionnaire.zip

[3] L. De Grez, M. Valcke and I. Roozen, "How effective are self- and peer assessment of oral presentation skills compared to teachers' assessments?" Active Learning in Higher Education, Vol. 13, No. 2, pp. 129-42, 2012.

[4] N. Falchikov and J. Goldfinch, "Student peer assessment in higher education: a meta-analysis comparing peer and teacher marks," Review of Educational Research, Vol. 70, No. 3, pp. 287-322, 2000.
[5] C.J. Finelli, I. Bergom, and V. Mesa, "Student Teams in the Engineering Classroom and Beyond: Setting Up Students for Success," University of Michigan, CRLT Occasional Paper 29, 2011.

[6] J.E. Froyd, P. C. Wankat, and K.A. Smit, "Five Major Shifts in 100 Years of Engineering Education," Proc. of the IEEE, Vol. 100, pp. 1344-60, May 13th, 2012.

[7] R. Graham, The global state of the art in engineering education. Cambridge, MA: Massachusetts Institute of Technology (MIT), 2018, 170 pp. $\quad\{$ ISBN 13:9780692089200\}

[8] A.T. Kirkpatrick, S. Danielson, and T. Perry, "ASME Vision 2030's Recommendations for Mechanical Engineering Education," Proc. 2012 ASEE Annual Conference and Exposition, 9 pp., San Antonio, 2012.

[9] D.B. Knight, E.F. Mappen, and S.L. Knight, "A Review of the Literature on Increasing the Representation of Women Undergraduates in STEM Disciplines through Civic Engagement Pedagogies," Science Education and Civic Engagement, Vol. 3, No. 1, 2011.

[10] S. Mattucci, J. Sibley, J. Nakane, and P.M. Ostafichuk, "A Model to Develop Peer Feedback Skills in First-Year Engineering Students," in Proc. Of CEEA 2017, 7 pp., Toronto, 2017.

[11] L.K. Michaelsen, A.B. Knight, and L.D. Fink (Eds.) Team-Based Learning: A transformative use of small groups in college teaching. Sterling, VA: Stylus (2004).

[12] P.M. Ostafichuk, C.P. Jaeger, J. Nakane, S. Nesbit, N. Ellis, J. Sibley, "Redesigning the UBC First Year Introduction to Engineering: Successes and Challenges," in Proc. of CEEA 2016, 8 pp., Halifax, 2016.

[13] J.E. Sibley, and P.M. Ostafichuk, Getting Started with Team-Based Learning. Sterling, Virginia: Stylus, 2014, 256 pp. \{ISBN: 978-1620361962\}

[14] K. J. Topping, "Peer Assessment," Theory Into Practice, Vol. 48, No. 1, pp. 20-27, 2009. 